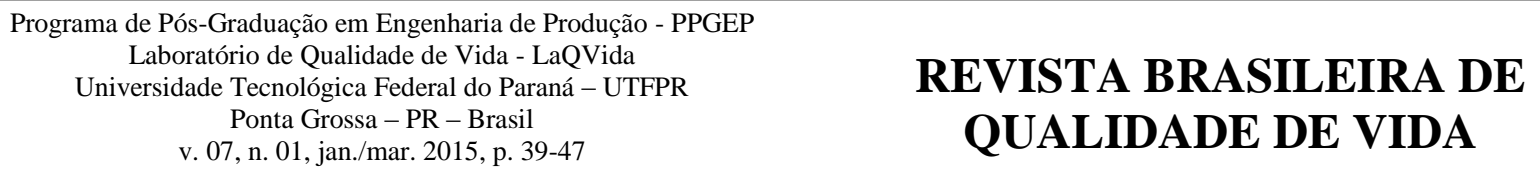

\section{REVISTA BRASILEIRA DE QUALIDADE DE VIDA}

\title{
As dimensões da qualidade de vida no trabalho expressas nas diretrizes organizacionais: um estudo sob a perspectiva de Walton
}

\section{The dimensions of quality of work life expressed in organizational guidelines: a study on Walton's perspective}

José André Villas Bôas Mello Centro Federal de Educação Tecnológica Celso Suckow da Fonseca - CEFET-RJ - Nova Iguaçu - Rio de Janeiro joseavbm@yahoo.com.br

Rômulo Henrique Gomes de Jesus Centro Federal de Educação Tecnológica Celso Suckow da Fonseca - CEFET-RJ - Nova Iguaçu - Rio de Janeiro Brasil romulohenriquegomes@hotmail.com

Andrea Justino Ribeiro Mello Centro Federal de Educação Tecnológica Celso Suckow da Fonseca - CEFET-RJ - Nova Iguaçu - Rio de Janeiro Brasil andreajribeiro@yahoo.com.br

\section{RESUMO}

OBJETIVO: Analisar a relação existente entre os melhores ambientes de trabalho no estado do Rio de janeiro e filosofias das empresas focadas aos seus colaboradores.

MÉTODOS: O presente estudo é descritivo. O corpus documental foi composto por registros disponíveis em arquivos públicos e através dos sítios na rede mundial de computadores das quatro empresas pesquisadas. Para classificação das empresas que possuem os melhores ambientes de trabalho foram utilizados dados da pesquisa anual de 2011, realizada pelo instituto Great Place to Work. A análise qualitativa observou os parâmetros propostos por Walton (1973).

RESULTADOS: Constatou-se que, considerando o modelo teórico de Walton, três organizações apresentam preocupações em cinco ou mais dimensões. Uma organização apresentou preocupação com apenas quatro dimensões. As dimensões mais valorizadas foram 'desenvolvimento das capacidades pessoais e do trabalho' e 'harmonia entre o trabalho e a vida social dos colaboradores'. As menos valorizadas foram 'exercicio da cidadania' e 'condições de trabalho'.

CONCLUSÕES: As empresas estudadas têm priorizado o desenvolvimento integral do trabalhador e sua vida dentro e fora do ambiente laboral.

PALAVRAS-CHAVE: Qualidade. Vida. Trabalho.

\section{ABSTRACT}

OBJECTIVE: Analyze the relationship between the best workplaces in the state of Rio de Janeiro and philosophies of companies focused on their employees. 
METHODS: This study is descriptive. The documentary corpus was composed of records available in public archives and through sites on the World Wide Web of the four companies surveyed. For the classification of companies with the best workplaces have been used data from the annual survey 2011, conducted by the Great Place to Work Institute. The qualitative analysis looked at the parameters proposed by Walton (1973).

RESULTS: It was found that, considering the theoretical model of Walton, three organizations have concerns on five or more dimensions. An organization showed concern with only four dimensions. The most valued dimensions were: development of personal skills and work and harmony between work and social life of the employees. The least valued were: exercise of citizenship and working conditions.

CONCLUSIONS: The companies studied have prioritized the integral development of the worker and his life inside and outside the workplace.

KEYWORDS: Quality. Life. Work.

\section{Introdução}

A competição no mercado empresarial tem feito com que as empresas modifiquem seus moldes organizacionais visando produtividade e melhores indicadores de desempenho. Além disso, segundo Campos (2004), estas mudanças organizacionais também são um reflexo da rápida evolução social, tecnológica e, sobretudo, mental que a sociedade vem experimentando.

Com o desenvolvimento industrial e as transformações ocorridas no trabalho, o homem deixou de ser visto como uma máquina, numa concepção que se voltava apenas para a produtividade, para ser visto como um colaborador que, ao ter satisfação com o trabalho, apresenta desempenho e eficiência superiores, contribuindo, dessa forma, com o sucesso das organizações. $\mathrm{O}$ foco na qualidade de vida no trabalho (QVT) se torna importante devido ao fato do trabalho ocupar um grande espaço na vida das pessoas, abarcando cerca de 8 horas por dia, durante, pelo menos, 35 anos de suas vidas.

Dessa forma, ao longo dos últimos anos, a valorização do trabalhador mostrou-se como uma das mudanças relevantes do mundo organizacional. Nesse aspecto, pode-se dizer que, cada vez mais, as organizações têm procurado influenciar seus funcionários na busca pela qualidade de vida (QV) dentro e fora do ambiente organizacional. Ou seja, as organizações têm tentado influenciar seus colaboradores a buscarem a saúde física, social e psicológica, através de investimentos em programas e em ações com esse foco.

Atrelado à satisfação e motivação dos trabalhadores, tendo em vista melhores índices de desempenho, o termo QVT popularizou-se entre acadêmicos e gestores organizacionais. A partir dessa constatação, o objetivo é analisar a relação existente entre os melhores ambientes de trabalho no estado do Rio de janeiro e filosofias das empresas focadas aos seus colaboradores. Para atender a esse objetivo foram selecionadas quatro empresas classificadas pelo Instituto Great Place to Work como detentoras dos melhores ambientes de trabalho, e a posterior análise de suas missões, programas e ações a fim de identificar seus atuais modelos organizacionais e sua relação com a QVT.

\section{Métodos e Materiais}

Esse estudo assumiu um caráter de pesquisa descritiva, baseando-se em registros disponíveis em arquivos públicos, que propiciaram a possibilidade de realização da coleta de dados através dos sites das empresas pesquisadas.

Para classificação das empresas que possuem os melhores ambientes de trabalho foram 
utilizados dados da pesquisa de Burchell e Robin (2011), publicada pelo Instituto Great Place to Work. Esta pesquisa foi escolhida por ser baseada em dados de mais de 10 milhões de funcionários em 45 países do mundo, representando mais de 5500 empresas de porte, indústrias e estruturas variáveis.

Das empresas listadas, se identificou as que estavam sediadas no estado do Rio de Janeiro, bem como dispunham de informações institucionais em seu website. Após a seleção das quatro empresas, buscou-se o estabelecimento de atributos de avaliação da QVT. Optou-se por abordar as oito dimensões para QV propostas no modelo desenvolvido por Walton (1973).

A análise documental planejada foi realizada através do conteúdo nos documentos institucionais centrando-se nas dimensões escolhidas. O objetivo da análise documental reside em extrair os elementos informativos de um documento original a fim de expressar seu conteúdo de forma abreviada, resultando na conversão de um documento primário em documento secundário. $\mathrm{O}$ procedimento adotado foi uma sistematização das respostas por meio de um controle preliminar de vocabulário, que viabilizou se determinar a relação entre a estratégia das organizações e as dimensões da QV.

\section{Revisão da Literatura}

\subsection{Mudanças no ambiente de trabalho}

As mudanças que ocorrem em relação aos aspectos socias, comportamentais e tecnológicos da sociedade em concomitância com a intensificação do dinamismo que o mundo enfrenta, refletem-se em modificações dos ambientes de trabalho, alterando a percepção de QV sob a ótica dos trabalhadores.

Slack, Chambers e Johnston (2008), por exemplo, descrevem em ordem cronológica, segundo a evolução das teorias da administração, as modificações ocorridas nos ambientes de trabalho em relação à execução de tarefas. Tais modificações apresentam-se da seguinte maneira:

a) divisão do trabalho - forte controle estabelecido sobre o trabalho realizado;

b) administração científica - controle sob os tempos e movimentos do trabalho realizado;

c) ergonomia - repensa a perspectiva de tempo e movimento e preocupa-se com as condições fisiológicas;

d) abordagens comportamentais - introdução das teorias motivacionais no ambiente de trabalho;

e) empowerment - o trabalhador passa a ter autonomia para implementar mudanças;

f) trabalho em equipe - funcionários desempenham coletivamente uma tarefa específica;

g) trabalho flexível - flexibilidade de horário e local de trabalho.

Nesse contexto, essas modificações estão ocorrendo de forma a possibilitar aos trabalhadores melhores condições referentes aos aspectos fisiológicos e psicológicos. No entanto, como toda empresa para sobreviver precisa ter lucros, essas modificações não ocorreram para oferecer melhores condições aos trabalhadores, mas para aumentar a produtividade e a qualidade dos produtos e serviços.

Segundo Alves et a. (1997), para aumentar a produtividade e conquistar novos mercados as empresas têm reformulado suas estruturas produtivas objetivando reduzir custos e melhorar a qualidade dos produtos. Estas modificações, de maneira geral, resultam na substituição dos princípios fordistas de produção (rigidez na divisão do trabalho, na prescrição individual de tarefas e na falta de autonomia dos colaboradores em relação aos métodos de trabalho) por novos princípios baseados na flexibilidade e na capacidade de oferecer respostas rápidas e eficientes às mudanças mercadológicas e às incertezas.

Para tal, exige-se profissionais multiqualificados, criativos e capazes de atuar cognitivamente, diferentemente do trabalhador fordista, cuja característica central quanto à 
execução de tarefas, conforme mencionado anteriormente, era a especialização e a repetitividade.

\subsection{Qualidade de vida no trabalho}

A QVT tem evoluído em paralelo com os diferentes ambientes de trabalho que surgem. Devido às rápidas mudanças nos âmbitos organizacionais, as empresas têm oferecido cada vez mais pacotes de benefícios e remunerações para seus funcionários, tornando o ambiente de trabalho cada vez melhor (ELIAS, 2011). Limongi-França (2009) destaca que toda pessoa é um complexo biopsicossocial, ou seja, tem potencialidades biológicas, psicológicas e sociais que respondem simultaneamente às condições de vida. Ainda cita que a QVT receba influencias de ações de uma empresa que envolvam diagnóstico e implantação de melhorias e inovações gerenciais, tecnológicas e estruturais no ambiente de trabalho.

Observa-se que QV independe das categorias profissionais em que o ser humano está inserido, mas é possível e factível existirem peculiaridades específicas (LUZ; TOSTA; MILANEZE, 2009). Sobre o modelo de Walton (1973), ele é constituído por oito dimensões e abrange aspectos básicos de situações no trabalho que funcionam como dimensões/critérios da QVT e são apresentadas e descritas no Quadro 1:

Quadro 1 - Critérios de Walton (1973) para qualidade de vida no trabalho

\begin{tabular}{|c|c|}
\hline Dimensões/Critérios & Descrição \\
\hline $\begin{array}{c}\mathbf{1} \\
\begin{array}{c}\text { Compensação justa e } \\
\text { adequada }\end{array}\end{array}$ & $\begin{array}{l}\text { Tem como objetivo analisar a remuneração recebida pelo trabalho } \\
\text { prestado: a) Remuneração adequada: remuneração necessária para o } \\
\text { funcionário ter uma vida digna; b) Equidade interna: quando todos os } \\
\text { funcionários da mesma equipe têm uma remuneração igual; c) Equidade } \\
\text { externa: igualdade na remuneração do funcionário em comparação com as } \\
\text { dos outros profissionais no mercado de trabalho. }\end{array}$ \\
\hline $\begin{array}{c}2 \\
\text { Condição de trabalho }\end{array}$ & $\begin{array}{l}\text { Tem o objetivo de medir a qualidade do local de trabalho: a) Jornada de } \\
\text { trabalho: se as quantidades de horas trabalhadas estão de acordo com o } \\
\text { serviço prestado pelo funcionário; b) Carga de trabalho: a quantidade de } \\
\text { trabalho deve ser realizada em um turno de trabalho; c) Ambiente físico: as } \\
\text { condições físicas do trabalho têm que ser confortáveis, organizadas e } \\
\text { saudáveis; d) Material e equipamento: todo o material necessário para o } \\
\text { serviço deve estar em boas condições e ter a quantidade certa para a sua } \\
\text { realização; e) Ambiente saudável: criar um ambiente saudável aos seus } \\
\text { funcionários; f) Estresse: tentar não criar um ambiente estressante para o } \\
\text { profissional. }\end{array}$ \\
\hline
\end{tabular}
Indicadores

Salário

Tem como objetivo verificar se o funcionário consegue aplicar os seus conhecimentos e aptidões profissionais: a) Autonomia: medida permitida ao funcionário de liberdade e independência na execução do seu trabalho; b) Significado da tarefa: o trabalho prestado deverá ser importante para o desenvolvimento de funcionário dentro e fora da empresa; c) Identidade da tarefa: medida do capacidades pessoais serviço prestado em sua integridade e no desempenho do resultado; d) Variedade da habilidade: verificar quais são as capacidades e habilidades do funcionário e utilizá-las; e) Retroinformação: fornecer um feedback aos Jornanda de trabalho, ambiente físico e salubridade funcionários.

\begin{tabular}{|c|c|c|}
\hline $\begin{array}{c}\mathbf{4} \\
\text { Oportunidades de } \\
\text { crescimento e } \\
\text { segurança }\end{array}$ & $\begin{array}{l}\text { Referente às oportunidades que a empresa fornece para o desenvolvimento, } \\
\text { o crescimento profissional e pessoal e a segurança do emprego dos seus } \\
\text { funcionários: a) Possibilidade de carreira: possibilidade de crescimento } \\
\text { profissional dentro da organização; b) Crescimento pessoal: possibilidade } \\
\text { de cursos e capacitação para o desenvolvimento dos funcionários; c) } \\
\text { Segurança de emprego: grau de segurança dos funcionários quanto às } \\
\text { chances de demissão da empresa. }\end{array}$ & $\begin{array}{c}\text { Carreira, } \\
\text { desenvolvimento } \\
\text { e estabilidade no } \\
\text { emprego }\end{array}$ \\
\hline $\begin{array}{c}\mathbf{5} \\
\begin{array}{l}\text { Integração social na } \\
\text { organização }\end{array}\end{array}$ & $\begin{array}{l}\text { Tem como objetivo verificar o grau de integração social que existe na } \\
\text { organização: a) Igualdade de oportunidades: todos na organização deverão } \\
\text { ter a mesma oportunidade; b) Relacionamento: medir o grau de } \\
\text { relacionamento interpessoal e o respeito às individualidades; c) Senso } \\
\text { comunitário: medir o consenso entre seus funcionários. }\end{array}$ & $\begin{array}{l}\text { Ausência de } \\
\text { preconceito, } \\
\text { habilidade social } \\
\text { e valores } \\
\text { comunitários }\end{array}$ \\
\hline
\end{tabular}




\begin{tabular}{|c|c|c|}
\hline $\begin{array}{c}\mathbf{6} \\
\text { Constitucionalismo / } \\
\text { Cidadania }\end{array}$ & $\begin{array}{l}\text { Verificar se a empresa está cumprindo todos os direitos dos funcionários; } \\
\text { a) Direitos Trabalhistas: ponderar se os direitos trabalhistas estão sendo } \\
\text { cumpridos; b) Privacidade Pessoal: observar o grau de privacidade, } \\
\text { existente dentro da organização, em relação aos seus funcionários; c) } \\
\text { Liberdade de expressão: se o funcionário tem a liberdade de se expressar; } \\
\text { d) Normas e rotinas: forma que as normas e rotinas interferem no } \\
\text { andamento do trabalho. }\end{array}$ & $\begin{array}{l}\text { Direitos } \\
\text { garantidos, } \\
\text { privacidade, } \\
\text { imparcialidade e } \\
\text { liberdade de } \\
\text { expresão }\end{array}$ \\
\hline $\begin{array}{c}7 \\
\text { Trabalho e espaço } \\
\text { total de vida }\end{array}$ & $\begin{array}{l}\text { Tem como objetivo medir a harmonia entre a vida pessoal e a vida } \\
\text { profissional do funcionário: a) Papel balanceado no trabalho: manter um } \\
\text { equilíbrio entre as horas trabalhadas e as reais necessidades de seu cargo; } \\
\text { b) Horário de entrada e saída do trabalho: o cumprimento das horas } \\
\text { trabalhadas e o convívio social. }\end{array}$ & $\begin{array}{l}\text { Vida pessoal } \\
\text { preservada e } \\
\text { horários } \\
\text { previsíveis }\end{array}$ \\
\hline $\begin{array}{l}\mathbf{8} \\
\text { Relevância social da } \\
\text { vida no trabalho }\end{array}$ & $\begin{array}{l}\text { Orientar seus funcionários sobre trabalhos sociais: a) Imagem da empresa: } \\
\text { se os empregados têm orgulho e satisfação de trabalhar na empresa; b) } \\
\text { Responsabilidade social da empresa: percepção do funcionário em relação } \\
\text { à responsabilidade social que a empresa presta a sua comunidade; c) } \\
\text { Responsabilidade social pelos serviços: percepção do funcionário em } \\
\text { relação à qualidade dos serviços prestado pela empresa para a comunidade; } \\
\text { d) Responsabilidade social pelos empregados: observar a política de } \\
\text { recursos humanos da empresa, verificando se há valorização e participação } \\
\text { do funcionário. }\end{array}$ & $\begin{array}{l}\text { Imagem da } \\
\text { empresa, } \\
\text { responsabilidade } \\
\text { social da empresa } \\
\text { e responsabilidade } \\
\text { social da empresa }\end{array}$ \\
\hline
\end{tabular}

Fonte: Adaptado de Alves (2010), Fernandes (1996) e Walton (1973).

Os oito critérios abordam com boa amplitude aspectos básicos de situações de trabalho e podem ser aplicados nos mais diferentes tipos de organizações (MAIER; SANTOS JUNIOR; TIMOSSI, 2012).

Para Burchell e Robin (2011), as empresas com os melhores ambientes de trabalho não são as que dão mais benefícios e mordomias para seus colaboradores, mas sim as que possuem líderes com habilidade de criar fortes relações de trabalho. No ambiente de trabalho adequado as pessoas confiam umas nas outras e têm orgulho do que fazem, assim como possuem boas relações com a equipe de trabalho. Estas relações são definidas como: employees and their leaders (funcionários e seus líderes); employees and their jobs (funcionários e seus trabalhos) e employees and each other (funcionários e seus colegas de trabalho). Na perspectiva de Burchell e Robin (2011), se os líderes das organizações criarem programas e políticas que contribuam para esses três tipos de relações, os trabalhadores terão um bom ambiente de trabalho.

Ainda de acordo com Burchell e Robin (2011), os fundadores do Instituto Great Place to Work, Robert Levering e Amy Lyman, criaram um modelo denominado de dimensões dos melhores ambientes de trabalho. Conforme modelo sugerido pelos fundadores, as três dimensões que devem ser atendidas para a criação de um bom ambiente de trabalho são: confiança, orgulho e amizade. A primeira dimensão - confiança - se subdivide entre credibilidade, respeito e justiça.

A QVT é uma temática atual de pesquisas, visto que pode criar informações que contribuam para o fortalecimento das relações entre os grupos de trabalho nas empresas. A QVT vai além de um bom salário ou um excelente cargo, abrangendo diferentes percepções sobre o ambiente de trabalho, como aspectos fisiológicos, psicológicos e sociais.

\subsection{Ações empregadas para proporcionar a qualidade de vida no trabalho}

Devido às frequentes mudanças ocorridas no cenário econômico, as empresas têm se empenhado cada vez mais para reter seus talentos, tomando atitudes que permitam construir um senso de família no trabalho (LEVERING; ERB, 2011).

Os melhores ambientes de trabalho vinculam o trabalho individual dos funcionários com as estratégias e os propósitos da empresa. Por exemplo, a Danone UK (Reino Unido) criou um programa voltado para profissionais, onde eles são desafiados a sonhar. Todo ano a empresa entrega aos funcionários um papel em forma de nuvem para que seja escrito um sonho, após isto, os papéis são colocados em um quadro que fica à vista de outros funcionários para que seja feita uma votação 
com o objetivo de saber qual sonho pode se tornar realidade através da empresa. O sonho mais votado recebe financiamento da empresa. Já foram realizados sonhos como arrecadação de dinheiro para um hospício de crianças e construção de uma casa na Cidade do Cabo, cidade natal de um funcionário (LEVERING; ERB, 2011).

É entendimendo na empresa Microsoft que, para demonstrarem seu potencial máximo, seus funcionários devem ser bem sucedidos na vida pessoal e na profissional. A empresa possui diversos programas voltados para os funcionários tais como: o programa Bump clup, no qual as futuras mães podem se cadastrar para receberem ajuda na preparação do nascimento do primeiro filho; o programa Bump to Balance no qual são ajudadas as mães a voltarem para seu trabalho após o nascimento do filho; e, o programa Keeping in Touch Days que disponibiliza um berçário na empresa para as mães manterem seus filhos enquanto trabalham (LEVERING; ERB, 2011).

De acordo com Elias (2011), com base na pesquisa realizada anualmente pelo Instituto Great Work Place, as melhores empresas para se trabalhar estão se aperfeiçoando, um dos mecanismos utilizados é a qualificação dos canais de comunicação entre líderes e empregados, além de pacotes de benefícios e remuneração para aumentar a satisfação e o empenho dos profissionais.

\section{Resultados e discussão}

Esse trabalho foi desenvolvido tendo como referência o trabalho de Burchell e Robin (2011), que apresentou uma lista das empresas classificadas como melhores ambientes de trabalho no mundo, dentre elas, quatro localizadas no estado do Rio de Janeiro, e selecionadas para esta pesquisa.

Em meio às empresas estudadas, se tem que, em 2011, a Radix Engenharia e Desenvolvimento de Software, possuia 167 colaboradores; a JW Marriot, 237; a Losango, 1150; e a Chemtech, 1287.

Para entender como o funcionário é visto pela organização, buscou-se informações a respeito da filosofia e das diretrizes organizacionais dessas empresas. Assim, as missões, os valores e os planos organizacionais foram identificadas em seus web sites.

A missão de uma empresa tem o propóposito de expressar a sua razão de existir. Em geral, são escritas com poucas palavras, dando ênfase ao mercado alvo, além de produtos e serviços que oferece, diferenciação do desempenho em relação a outras empresas e conquistas futuras. Dessa maneira, a missão da empresa reflete o que é a empresa de maneira clara e objetiva.

Como pode ser observado no Quadro 2, todas as empresas pesquisadas apresentam a preocupação de investir em seus funcionários através de desenvolvimento contínuo, agregação de valor e crescimento profissional, conforme se evidencia na missão das empresas.

\begin{tabular}{|c|l|}
\hline \multicolumn{2}{|c|}{ Quadro 2- Diretrizes organizacionais } \\
\hline EMPRESA & \multicolumn{1}{c|}{ MISSÃO/VALORES } \\
\hline Radix & $\begin{array}{l}\text { Oferecer serviços de engenharia e software diferenciados pela excelência técnica e ética e com } \\
\text { independência tecnológica, ampliando os valores gerados para clientes, funcionários e sócios, a } \\
\text { partir de um compromisso de longo prazo firmado com a sociedade, o País e o meio ambiente. }\end{array}$ \\
\hline \multirow{3}{*}{ JW Marriot } & $\begin{array}{l}\text { Oferece oportunidades à: } \\
\text { Pessoas - Crescimento pessoal e profissional } \\
\text { Clientes - Gratificantes experiências de viagem } \\
\text { Proprietários e franqueados - investimentos rentáveis } \\
\text { Investidores - realização financeira } \\
\text { Alianças de colaboração comercial - Com fornecedores e outros relacionamentos chave } \\
\text { Comunidades - Um futuro mais sustentável nos locais onde vivemos e trabalhamos }\end{array}$ \\
\hline & $\begin{array}{l}\text { Ser a melhor promotora de vendas de produtos e serviços financeiros para o varejista, } \\
\text { oferecendo soluções integradas que agreguem valor a toda cadeia produtiva: consumidores } \\
\text { finais, varejistas, colaboradores e acionistas, proporcionando o crescimento com qualidade e } \\
\text { resultados sustentáveis. }\end{array}$ \\
\hline
\end{tabular}



industrial, gerando valor para nossos clientes, com foco no desenvolvimento de parcerias de longo prazo e baseado no desenvolvimento contínuo de nossos funcionários.

$$
\text { Fonte: Autoria própria (2014). }
$$

Neste contexto, nota-se que as quatro empresas pesquisadas citaram seus colaboradores como um dos foco do business da organização, ressaltando a preocupação que a empresa possui com os seus colaboradores. Em seguida, são apresentadas no Quadro 3 informações relativas aos programas e ações oferecidos aos colaboradores e que podem ser relacionados à preocupação com a QVT devido à sua perspectiva.

Quadro 3 - Programas e ações das empresas que tem a perspectiva nos funcionários

\begin{tabular}{|c|c|}
\hline Empresas & Programas e ações com perspectiva nos funcionários \\
\hline Radix & $\begin{array}{l}\text { Patrocina e participa de eventos esportivos e projetos de inclusão social além de incentivar a prática } \\
\text { de esporte entre os funcionários. Alguns eventos que já foram apoiados são: circuito das estações } \\
\text { Adidas (participação da equipe de corrida da empresa); patrocinio de atletas de vôlei de praia Talita } \\
\text { e Maria (incentivando um estilo de vida mais saudável, inclusive junto aos funcionários. Se cria } \\
\text { uma cultura do esporte e a favor da QV, com os funcionários se sentindo orgulhosos, pois têm } \\
\text { acesso aos atletas patrocinados nos encontros organizados); projeto praia para todos (empresa é } \\
\text { mantenedora do Instituto Novo Ser, que organiza o projeto que tem como objetivo aumentar a } \\
\text { integração da pessoa com deficiência com a natureza e o esporte, promover mais sociabilidade e, } \\
\text { despertar a atenção da opinaão pública que não oferece estrutura adequada na cidade olimpica, } \\
\text { integrantes do coral da Radix já participaram das atividades), entre outros. }\end{array}$ \\
\hline $\begin{array}{c}\text { JW } \\
\text { Marriot }\end{array}$ & $\begin{array}{l}\text { Pacotes de benefícios competitivos (que pode variar por país de acordo com as leis e práticas de } \\
\text { emprego) em que os funcionários da Marriott podem desfrutar de: valiosa tarifa de quarto, } \\
\text { alimentos e bebidas, varejo e descontos em hoteis globais Marriott; empregados com } 25 \text { anos de } \\
\text { serviço ganham um fim de semana grátis para permanecer em qualquer hotel da Marriott ao redor } \\
\text { do mundo. }\end{array}$ \\
\hline Losango & $\begin{array}{l}\text { Programa de ambientação: Neste programa, os novos integrantes da Losango têm acesso a uma } \\
\text { nova visão da organização, valores, estratégias, produtos e serviços. Dessa forma, passam a } \\
\text { conhecer o negócio e tornam-se jogadores talentosos no time. } \\
\text { Desenvolvimento: A Losango propicia uma cultura voltada ao conhecimento e à atualização } \\
\text { permanentes, oferecendo desafios e oportunidades de desenvolvimento a todos os seus } \\
\text { funcionários. Por isso, dentro da Losango se desenvolve os colaboradores através diferentes } \\
\text { mecanismos, e não somente de cursos e treinamentos, mas também com o convívio social e com a } \\
\text { realização das atividades e projetos. Além disso, a Losango possui um ótimo ambiente de trabalho, } \\
\text { onde o relacionamento entre as pessoas é valorizado como ponto fundamental para o sucesso. } \\
\text { Remuneração e benefícios: A Losango pratica uma remuneração competitiva com o mercado, } \\
\text { quando comparada com as grandes empresas atuantes no Brasil. Além do salário fixo, os } \\
\text { funcionários recebem uma participação nos lucros e resultados da empresa. A Losango oferece } \\
\text { ainda uma série de benefícios aos seus funcionários: assistência médica; assistência odontológica; } \\
\text { vale-refeição/alimentação; plano de previdência privada; seguro de vida; e, assistência funeral. }\end{array}$ \\
\hline Chemtech & $\begin{array}{l}\text { A política da Chemtech é priorizar o desenvolvimento de todos os colaboradores, para que possam } \\
\text { assumir cargos de liderança e de especialização técnica. O modelo de crescimento profissional da } \\
\text { Chemtech é a carreira em Y, na qual os funcionários podem escolher entre seguir a carreira } \\
\text { gerencial (atuando como líderes de projetos, gerentes de projetos e gerentes seniores) e a carreira } \\
\text { técnica que é subdividida em duas: gestão (líderes, gerentes de disciplinas e gerentes seniores) e } \\
\text { especialização técnica (especialistas, consultores e consultores seniores). } \\
\text { Benefícios e bem estar: Além de oferecer todos os benefícios previstos por lei, a Chemtech } \\
\text { disponibiliza ainda para todos os seus colaboradores convênios e conveniências exclusivas. Entre } \\
\text { os destaques estão o plano de previdência privada, plano de ações, licença maternidade de seis } \\
\text { meses, auxílio creche e natalidade, assistência médica e odontológica e horário flexível. Além } \\
\text { disso, a Chemtech está sempre promovendo atividades de bem-estar para todos os seus } \\
\text { funcionários, tais como aulas de dança, instrumentos, vôlei, grupos de corrida, futebol, } \\
\text { massoterapia, entre outras. }\end{array}$ \\
\hline
\end{tabular}

Fonte: Autoria própria (2014).

Observando o Quadro 3 constata-se que é possível criar projetos sociais e programas com foco no estilo de vida e na expectativa da disseminação dos estímulos focados na QV dos 
funcionários e da sociedade. Neste contexto, a Radix e a Chemtech buscam envolvê-los com a prática de esportes, enquanto a JW Marriot utiliza a sua expertise em hotelaria e fornece aos seus funcionários a opção de desfrutar de seus serviços em um hotel da rede em qualquer lugar do mundo e a Losango fornece um programa de ambientação, desenvolvimento, remuneração e benefícios.

Com o objetivo de analisar a relação dos dados obtidos no Quadro 2 com os dados do Quadro 3, fundamentando-se nas dimensões de Walton (1973) e considerando as observações como variáveis binomiais (observadas ou não observadas), estruturou-se o Quadro 4, onde as variáveis observadas foram assinaladas com um X.

\begin{tabular}{|c|c|c|c|c|c|c|c|c|}
\hline & $\begin{array}{c}\text { Compensação } \\
\text { justa e } \\
\text { adequada }\end{array}$ & $\begin{array}{c}\text { Condições de } \\
\text { Trabalho }\end{array}$ & $\begin{array}{c}\text { Uso e } \\
\text { desenvolvimento } \\
\text { das capacidades } \\
\text { pessoais }\end{array}$ & $\begin{array}{c}\text { Oportunidade } \\
\text { de } \\
\text { crescimento e } \\
\text { segurança }\end{array}$ & $\begin{array}{c}\text { Integração } \\
\text { social na } \\
\text { organização }\end{array}$ & Cidadania & $\begin{array}{l}\text { Trabalho e } \\
\text { espaço total } \\
\text { de vida }\end{array}$ & $\begin{array}{l}\text { Relevância } \\
\text { social do } \\
\text { trabalho }\end{array}$ \\
\hline Radix & & & $x$ & & $\mathrm{x}$ & & $\mathrm{x}$ & $\mathrm{x}$ \\
\hline Jw Marriot & & & $\mathrm{x}$ & $\mathrm{x}$ & $\mathrm{x}$ & & $\mathrm{x}$ & $\mathrm{x}$ \\
\hline Losango & $x$ & & $x$ & $\mathrm{x}$ & $\mathrm{x}$ & $x$ & $x$ & $x$ \\
\hline Chemtech & $x$ & $\mathrm{x}$ & $x$ & $x$ & & & $x$ & \\
\hline $\begin{array}{c}\text { Intensidade } \\
\text { das } \\
\text { caracteristicas } \\
\text { observadas }\end{array}$ & 2 & 1 & 4 & 3 & 3 & 1 & 4 & 3 \\
\hline
\end{tabular}

Fonte: Autoria própria (2014).

Considerando os dados apresentados no Quadro 4 chegou-se à Figura 2, na qual pode-se visualizar a representatividade das dimensões perante a intensidade das características observadas. De acordo com a Figura 2, pode-se observar que as principais tendências das dimensões de Walton (1973) a serem atendidas pelas empresas com o intuito de proporcionar um bom ambiente de trabalho, conforme informações coletadas dos sites das instituições, são: as dimensões do uso e desenvolvimento das capacidades pessoais e trabalho e espaço total de vida, ambos observadas nas quatro organizações.

Figura 2- Representatividade das dimensões

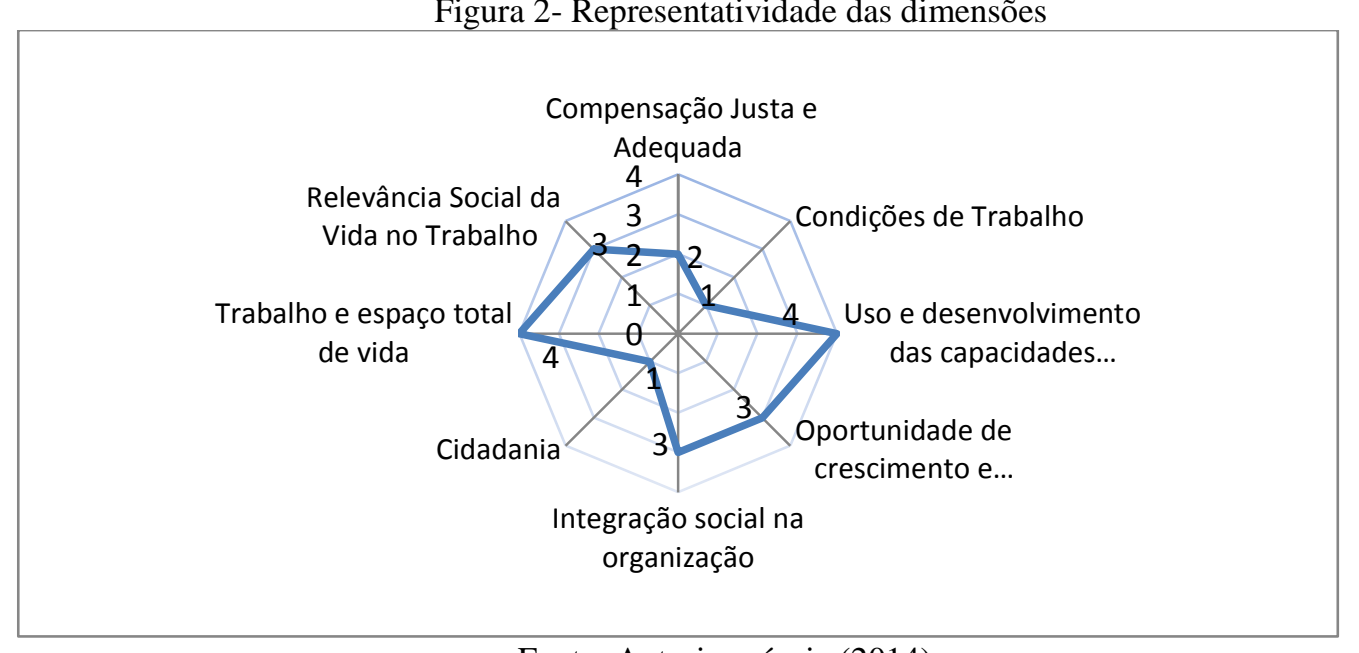

Fonte: Autoria própria (2014). 
As dimensões de relevância social da vida no trabalho, integração social na organização e oportunidade e segurança foram observadas em três do total de quatro empresas, demostrando que as empresas estão se preocupando em desenvolver seus funcionários, garantindo a integração social e, em algumas, inserindo-os na condição de protagonismo. Apenas uma empresa apresentou preocupação com quatro das oito dimensões. Quanto às dimensões o exercicio da cidadania e às condições de trabalho são as menos valorizadas, e das mais valorizadas se tem o desenvolvimento das capacidades pessoais e do trabalho e a harmonia entre o trabalho e a vida social dos colaboradores.

Este fato evidencia a preocupação que as empresas têm tido com a qualificação profissional de seus funcionários. Com somente uma observação, tendo como referencia às quatro empresas estudadas, apresentaram-se as dimensões de condições de trabalho e cidadania. Este valor foi obtido devido ao fato que os indicadores dessa dimensão são: ambiente físico, salubridade, jornada de trabalho, direitos garantidos, privacidade, imparcialidade e liberdade de expressão. Como são indicadores em que sua presença é mais notável através da observação in loco ou da realização de entrevistas com os funcionários das organizações pesquisadas, não foi possível a constatação dos mesmos. Pode-se dizer, dessa forma, que este fato atua como um limitador da pesquisa já que a metodologia empregada se baseou em dados disponibilizados nos sítios das organizações.

De uma maneira geral, o trabalho alcançou seu objetivo. Concluiu-se que que, no contexto das quatro organizações estudadas, os melhores ambientes para se trabalhar são onde há um bom trabalho e espaço total de vida, tendo como reflexo pessoas motivadas. Como também há a presença de programas que incentivam a prática de esportes, dança e massoterapia. Vislumbra-se que o convívio social de fato é um dos elementos identificados. O estudo permite até mesmo inferir que uma matriz lógico-linguística auxilia a ciência na reflexão teórico-conceitual sobre o tema QVT.

\section{Referências}

ALVES, E. L. G.; SOARES, F. V.; AMORIM, B. M. F.; CUNHA, G. H. M. Modernização produtiva e relações de trabalho: perspectivas de políticas públicas. Brasília: Instituto de Pesquisa Econômica Aplicada, 1997.

ALVES, N. R. A Qualidade de vida no trabalho dos funcionários terceirizados do CENTRESAF/DF. 2010. 43 f. Monografia (Graduação em Administração) - Centro Universitário de Brasília, Brasilia, 2010.

BURCHELL, M.; ROBIN, J. The great workplace, how to build it, how to keep it and why it matters. San Francisco: Jossey-Bass, 2011.

CAMPOS, V. F. TQC controle da qualidade total (no estilo japonês). 8. ed. Minas Gerais: INDG, 2004.

ELIAS, J. As empresas ficam melhores para trabalhar. Revista Época, Rio de Janeiro, out. 2011. Disponível em: <http://revistaepoca.globo.com/Negocios-ecarreira/GPTW/noticia/2011/08/empresas-ficaram-melhores-para-trabalhar.html>. Acesso em: 08 abr. 2012.

FERNANDES, E. Qualidade de vida no trabalho: como medir para melhorar. 3. ed. Salvador: Casa da Qualidade, 1996. 
LEVERING, R.; ERB, M. Emerging trends in people management. The best workplaces continue to find innovative ways to create personal and meaningful connections with their employees. Swiss Business, p. 30-33, Jan./Feb. 2011. Disponível em:

<http://en.greatplacetowork.ch/storage/documents/Publications_Documents/2010_Emerging_Trends_In_People_Management.pdf>. Acesso em: 07 abr. 2011.

LIMONGI-FRANÇA. Qualidade de Vida no Trabalho - QVT: conceitos e práticas nas empresas da Sociedade pós-industrial. 2. ed. São Paulo: Atlas, 2009.

LUZ, M. M.; TOSTA, K. C. B. T.; MILANEZE, C. Qualidade de vida no trabalho: o caso dos servidores do ambulatório do Hospital Universitário da Universidade Federal de Santa Catarina. In: COLÓQUIO INTERNACIONAL SOBRE GESTÃO UNIVERSITÁRIA NA AMÉRICA DO SUL, 4., Florianópolis. Anais.. Florianópolis: UFSC, 2009.

MAIER, R. C.; SANTOS JUNIOR, G.; TIMOSSI, L. S. Análise das influencias existentes entre qualidade de vida e qualidade de vida no trabalho: estudo com colaboradores da indústria de laticínios. Revista Gestão Industrial, v. 8, n. 2, p. 265-280, abr./jun. 2012.

SLACK, N.; CHAMBERS, S.; JOHNSTON, R. Administração da produção. 2. ed. São Paulo: Atlas, 2008.

WALTON, R. E. Quality of working life: what is it?. Sloan Management Review, v. 15, n. 1, p. 11-21, 1973. 